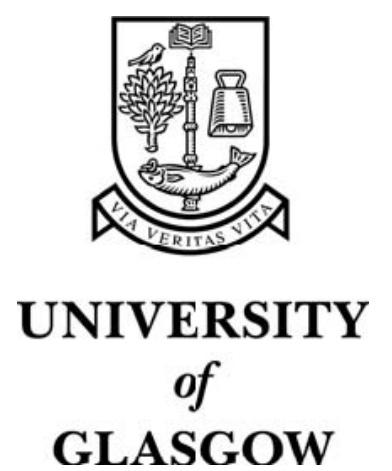

Renaud, K. and Dyk, T. (2001) Tailoring e-commerce sites to ease recovery after disruptions. In, 25th Annual International Computer Software and Applications Conference, 2001, 8-12 October 2001, pages pp. 603-608, Chicago, Illinois.

http://eprints.gla.ac.uk/3654/ 


\title{
Tailoring E-Commerce Sites to Ease Recovery after Disruptions
}

\author{
Karen Renaud \& Tobias van Dyk \\ Department of Computer Science, University of South Africa \\ $\{$ renaukv,vdyktj\}@unisa.ac.za
}

\begin{abstract}
Developers of e-commerce applications are often unrealistic about how their site will be used, and about possible outcomes during site usage. The most commonly considered outcomes of a user's visit to a site are firstly that the visit culminates in a sale, and secondly that the user leaves the site without buying anything - perhaps to return later. In the second case sites often "remember" any accumulated items so that a shopper can return at a later stage to resume shopping.

In this paper we consider certain disruptions, such as breakdowns, problems caused by human errors, and interruptions, which could affect the outcome of the e-commerce shopping experience. These events have definite and possibly long-lasting effects on users, and applications should therefore be developed to cater for these eventualities so as to enhance the usability of the site and encourage further usage.

We develop a model for analysing e-commerce application usage, and using this model, propose an evaluation strategy for determining whether an e-commerce site will be resistant to such factors. The proposed evaluation mechanism is applied to three sites to arrive at what we shall call a disruption-resistance score.
\end{abstract}

\section{Introduction}

E-commerce has tremendous potential, and can benefit both seller and buyer. Buyers are no longer restricted to shopping at certain times or within certain geographical locations $[5]$. E-commerce offers wonderful opportunities to buyers with limited mobility or other difficulties which make shopping arduous. Organisations do not have to be concerned about shoplifting and can offer a better level of service without having to pay vast armies of sales staff [15].

One aspect of e-commerce sites which is not addressed in current research is that users can seldom use any system without being interrupted either by something in their environment, or by an error. Errors could result from a break- down in one of the systems involved in the distributed application, or from errors made by the user. The user will often need assistance in recovering from these disruptions to their primary task.

This paper will address the disruption resistance of ecommerce sites. Section 2 will discuss the research into human error recovery while Section 3 will explore recovery from interruptions. Section 4 will consider breakdowns and how sites can make things easier for users in the face of these inevitable service disruptions. This paper proposes an evaluation mechanism to ensure that web-sites assist users in recovering from disruptive events. Before such a methodology can be provided it is necessary to understand the nature of the e-commerce shopping experience, so this will be discussed in Section 5 . Section 6 proposes the disruption-resistance evaluation methodology for e-commerce systems. Section 7 discusses the results of an evaluation which was conducted on three large e-commerce sites. Section 8 concludes.

\section{Human Error Recovery}

Very few e-commerce users will be skilled in data entry and we can therefore expect that many errors will be made. E-commerce systems should assist users in recovering from their errors in a graceful fashion.

Most systems react to errors by generating error messages, but error messages are not necessarily the solution to the problem. The difficulty with error messages is well known, for instance $[4,6]$ :

- The format and tone of the error message often undermine the user's self-confidence.

- The messages will often make people believe they have committed some serious error and that they are incompetent.

- Messages sometimes supply insufficient information.

- Messages often give obscure codes or use jargon. 


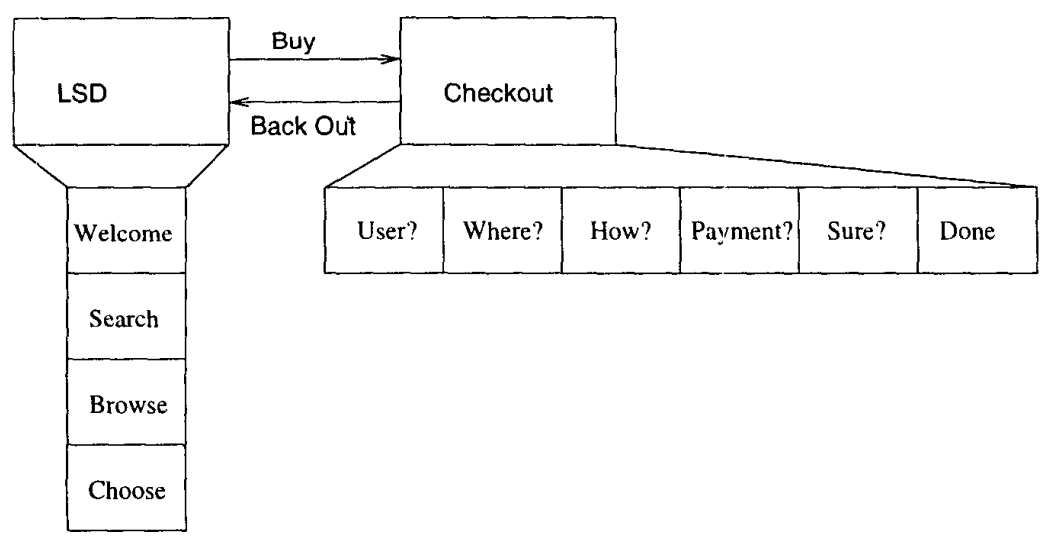

Figure 1. The Two Phases and Ten Stages of The Purchase Task

Customers using e-commerce sites are often doing so in order to look at products and decide whether to buy something or not. The desired outcome, from the organisation's point of view, is that a transaction will result. It should be easy for a user to recover from mistakes if he or she is not to be alienated. A number of web pages will be traversed before a user commits to a sale - generating a transaction for the e-commerce site - thus the entire site experience must be rewarding, and attention should be given equally to each page.

There is a need for great care to be exercised when designing e-commerce systems - so that the user is given every opportunity to realise when errors have been made, facilitating rapid and painless backward recovery. Backward recovery is always a better option than forward recovery - and this is facilitated by providing the user with every opportunity to realise the consequences of their actions so that errors can be detected before a transaction is completed. Should an error be undetected, the system can make life much simpler by making the user's forward recovery process as painless as possible.

\section{Recovery from Interruptions}

Cypher explains that when a user is busy with some activity, he or she builds up a context [1]. The context is a rich mental environment that stores all sorts of information that has been built up using that particular system to execute some task. Cypher points out that even a momentary interruption will lead to the collapse of this mental context.

After the interruption has been dealt with, the user then needs to change context again, and decide which task to proceed with. In some cases, the user will resume the original task, but in $45 \%$ of cases (O'Connaill \& Frohlich [11]), the user will not resume the disrupted task.

What is required in alleviating the negative effects of interruptions is assistance in re-establishing context. A mere list of the sites visited, as provided by most browsers, is too coarsely grained to be much use, because users cannot be expected to remember the different and often dynamically generated web pages within the site. Most browsers offer a "back" button to allow users to check previous interactions with the system. However, using the "back" button may change the state of the system, which is likely to have negative side-effects and affect transaction validity. Rather than relying on the universal browser-supplied 'back' button, it would be better for the application explicitly to provide a history facility as part of their user interface and systems architecture.

\section{Brealkdowns}

Since an e-commerce transaction requires that at least two nodes should function one can consider a breakdown from two perspectives - client and server. A user who is currently searching for a particular product and who has, by a process of elimination, arrived at that product by entering the correct search criteria will be annoyed if their computer or browser crashes and they lose their context in the e-commerce site. While it is unrealistic to expect all context to be kept, merely providing a list of previous search criteria would go a long way towards helping the user pick up the threads.

It is incredibly difficult to report breakdowns in a constructive way because their source is often difficult to identify and the remedy is usually not obvious. Developers should avoid lapsing into jargon - the user should be made aware that there is a problem, and be told whether to con- 
tinue use of the system immediately or whether to try again later.

\section{Analysis of the E-Commerce Purchasing Experience}

Guttman et al. [2] identify six stages of customer purchasing behaviour: need identification, product brokering, merchant brokering, negotiation, purchase and delivery, and service and evaluation. O'Keefe and McEachern [12] propose a model with only five processes: need recognition, information search, evaluation, purchase, and after-purchase evaluation. Singh et al. [20] break up the e-commerce process into three activities: indentifying a vendor, purchasing and tracking.

We will examine only one of Singh's processes namely the one that everyone refers to as the purchase task, which can be split up into two distinct phases, as shown in Figure 1:

1. LSD - Look, See and Decide. This phase will typically be used to look at available products, compare them, and to make a decision about whether or not to purchase products. This phase is user-driven. The system merely attempts to support the searching and browsing process so that it renders the products the user is looking for. This phase has the following stages which can be traversed iteratively and in varying sequences: Welcome, Search, Browse, and Choose.

2. Checkout. When users trigger this phase they have made their choice of offered products and decided to purchase one or more products. They now have to provide certain details, such as their address and credit card details, and make choices about things such as gift wrapping and shipping requirements. This phase is system-driven and changes the paradigm of the interaction process from user initiative to system initiative.

This phase is typically composed of at least the following stages, which should be navigated in a serial fashion: User? Where? How? Payment? Sure? and Done.

Interruption of the LSD phase is catered for by most sites by means of cookies. The disruption-resistance needs of these two phases are sufficiently different to require them to be considered separately, as we will do in the following section.

\section{Method}

Most e-commerce stores make use of a shopping basket and cookies in order to ensure that the basket details are kept available over a period of time, thus already catering for possible disruption during the LSD phase. There is, however, little support for disruptions during the checkout process.

Suitable elements from the most applicable of Ravden and Johnson's [16] categories have been selected in order to set up one complete disruption-resistance evaluation mechanism, for each stage, which will ensure that an e-commerce page provides adequate support for recovery from disruptions. The evaluation metrics for the LSD phase are:

1. Does the system inform the user of the reasons for delays? $[7,8,11,10]$

2. Can the user easily undo a product selection? [10,11]

3. Does the system allow users to check on previous searches? $[18,21]$

Metrics for the checkout phase are:

1. Is the required format of user inputs clearly indicated? [13]

2. Is it clear what changes in the system have taken place as a result of a user action? [19]

3. Does the system inform the user of the success or failure of their actions?

4. Does the system inform the user of the reasons for delays? $[7,8]$

5. Do error messages indicate [17]:

(a) What errors are?

(b) Where errors are?

(c) Why they have occurred?

(d) What the user must do to recover?

6. Is it clear what the user has to do to complete the task?

7. Does the system indicate the current stage in the checkout process [21]

8. Was information clearly available? $[3,13]$

9. Can the user easily back out of the process? $[7,8]$

10. Does the system ensure that the final purchase is confirmed by the user?

11. Does the system allow users to check on inputs provided during the process? [18] 


\begin{tabular}{|c|c|c|c|}
\hline Evaluation of Disruption Resistance: LSD Stage & $\begin{array}{c}\text { Amazon } \\
\max 9\end{array}$ & $\begin{array}{c}\text { Kalahari } \\
\max 9\end{array}$ & $\begin{array}{l}B \bar{B} \\
\max 9\end{array}$ \\
\hline Does the system inform the user of the reason for delays? & 5 & 3 & 3 \\
\hline Can the user easily undo a product selection? & 9 & $\overline{6}$ & $\overline{8}$ \\
\hline Does the system allow users to check on previous searches? & 0 & 0 & 0 \\
\hline Percentage: & $52 \%$ & $33 \%$ & $41 \%$ \\
\hline
\end{tabular}

Table 1. Evaluation Metrics for the L.SD Stage

The following section will describe how these metrics were applied to three e-commerce sites, and comment about the efficacy of the proposed evaluation mechanism. In order to evaluate e-commerce Web pages, a score is given for each of the above questions as follows: Never (0), Sometimes (1), Mostly (2), or Always (3). The scores are then determined per stage, and then per phase, and lastly per site, in the form of a percentage where $100 \%$ indicates a site giving a user perfect disruption-recovery support whilst sites scoring $0 \%$ might as well give up. The scores per feature in each phase were calculated by adding up the score for each page making up the stage and awarding a total for each particular feature. The scores were then totalled to arrive at a percentage per site per purchasing stage.

\section{Evaluation}

We chose three sites to apply the metrics to. In choosing the sites we tried to find sites which sold similar products so that the evaluation would be more meaningful. Booksellers like Amazon ( $w w w$. ama zon . com) are the pioneers in this field and we felt that their site would be a good one to evaluate. We therefore chose two other bookseller's sites to compare it to - namely Books Online (www. uk . bo 1, com) and Kalahari (www . kalahari . net). Our final scores for each site are given in Tables 1 and 2.

\subsection{Discussion}

One notices from Tables 1 and 2 that certain metrics scored markedly well or badly. A low score should wave a red fiag at the developer and indicates a problem area. A high score shows that the developer has done a good job in providing adequate disruption resistance for that particular feature of the site. This section will discuss the good and bad features of the three sites.

\subsubsection{Low Scores}

Two criteria stand out particularly: the lack of a history facility which facilitates easy resumption, and inadequate explanations for long or unexpected delays. None of the evaluated sites allow users to remind themselves of previous search criteria. In the same vein, there is also a need for the user to be reminded, as they progress through the checkout stage, of their previous inputs. Some sites do provide this but it is usually not done consistently.

The other controversial score is the one allocated to the question: Does the system inform the user of the reasons for delays?. All popular browsers give observable feedback on page-fetch delays and anticipated completion times. However, many sites, including the ones evaluated, seem to rely completely on this facility rather than providing the user with some sort of site-specific indicator of site access (hitrate). A user who is given access to such an indicator will perhaps be more patient when sites are slow to respond.

A feature which we had considered to be essential and basic to good practice, namely that of indicating the substage throughout the checkout stage, was almost absent in the Kalahari site. The users become disoriented because the checkout stage encompasses various similar substages and they have no easy way of knowing where they are in the process - especially if he or she is interrupted. In defence of Kalahari, it must be said that their checkout phase has only three substages and the developers might have decided that an indicator was superfluous. We do not agree. When one uses Amazon and BOL one is struck by how helpful this indicator is.

\subsubsection{High Scores}

A feature in all evaluated sites is the requirement that users positively re-confirm their transactions. This offers the opportunity for backward recovery. All sites also send the user an e-mail confirming the order so that the user can exercise a form of forward recovery, via e-mail.

\subsubsection{Interesting and Noteworthy Features}

Kalahari has an interesting feature with both good and bad aspects. A summary of the user's basket is displayed on the search page. In terms of resumption after a disruption this is a very good feature but it must slow down the page-fetch time since it has been implemented in a graphical manner. 


\begin{tabular}{|c|c|c|c|c|c|}
\hline \multicolumn{3}{|c|}{ Evaluation of Disruption Resistance: Checkout Stage } & $\begin{array}{l}\text { Amazon } \\
\max 18\end{array}$ & $\begin{array}{l}\text { Kalahari } \\
\max 9\end{array}$ & $\max 15$ \\
\hline 1 & \multicolumn{2}{|c|}{ Is the nequined format of user inputs clearty indicated? } & 15 & 7 & 10 \\
\hline 2 & \multicolumn{2}{|r|}{$\begin{array}{l}\text { Is it clear what changes in the system have taken place as a result of user } \\
\text { action? }\end{array}$} & 13 & 6 & 12 \\
\hline 3 & \multicolumn{2}{|r|}{ Does the system inform users of the success or failune of their actions? } & 14 & 6 & 11 \\
\hline 4 & \multicolumn{2}{|c|}{ Does the system inform the user of the reasons for delays? } & 11 & 3 & 5 \\
\hline 5 & \multicolumn{2}{|c|}{ Do error messages indicate: } & & & \\
\hline & 5.1 & What emors ane? & 12 & 6 & 13 \\
\hline & 5.2 & Whitere entors are? & 6 & 3 & 10 \\
\hline & 5.3 & Why they have occumed? & 6 & 1 & 13 \\
\hline & 5.4 & What the user must do to recourer? & 10 & $\overline{6}$ & 8 \\
\hline 6 & \multicolumn{2}{|c|}{ Is it clear what the user has to do to complete the task? } & 11 & 5 & 14 \\
\hline 7 & \multicolumn{2}{|r|}{ Does the system indicate the current stage in the checkout process? } & 17 & 3 & 15 \\
\hline 8 & \multicolumn{2}{|c|}{ Mas information cleary arailable? } & $\overline{\mathbf{g}}$ & 6 & 12 \\
\hline 9 & \multicolumn{2}{|c|}{ Can the user easily back out of the process? } & 10 & 2 & 3 \\
\hline 10 & \multicolumn{2}{|r|}{ Does the system ensure that the final punchase is confimed by the user? } & 18 & 9 & 15 \\
\hline 11 & \multicolumn{2}{|r|}{ Does the system allow users to check on inputs provided during the process? } & 9 & G & 3 \\
\hline & & Percentage: & 6496 & $55 \%$ & $69 \%$ \\
\hline
\end{tabular}

Table 2. Evaluation Metrics for the Checkout Stage

This is unfortunately one of the problems that must be addressed in providing feedback to support recovery from disruptions - one must always weigh a good feature against the cost thereof.

BOL scored better than Amazon mainly due to its superior error-handling facilities. It also has a very interesting feature which is activated during the checkout stage. Users can link up directly to a customer service desk for online help. This is a smart move by BOL because an error-free completion of this stage is more likely to lead to a sale. BOL has obviously realised the folly of losing users at this stage and attempts to offer help by providing personal service. Unfortunately $\mathrm{BOL}$ has not exploited its innovation very well because it restricts online help to daytime hours, and assumes that users will be in the same time zone by not explicitly linking their times to GMT. It is also unfortunate that BOL lapses into jargon when the online chat feature is activated. The activated window instructs the user to Javaenable his or her browser, but doesn't give any instructions on how this may be achieved. It is also a pity that when one of the authors connected to ask a question at midday, no one replied. The whole idea of EC is to free users from restrictions of times and place and if BOL is to have any chance of challenging other large e-commerce sites it will have to improve on this very innovative facility.

\section{Conclusion}

In this paper the structure of the purchasing stage of $e$ commerce was investigated. We have identified two distinct and dissimilar phases during the shopping cycle and have applied stage-specific evaluation metrics to them. The effects of errors, interruptions and breakdowns have been explored, and ways to support the user in recovering from such disruptions have been proposed.

Nielsen [9] avers that the purpose of usability studies is to set the tone for a new design direction. Thus an evaluation mechanism was proposed which can be used by developers to analyse their sites so that problem areas can be identified and sites thereby made more resistant to disruptions. Similarly, for areas that perform well, even more of an effort should be made to maintain and improve the existing high standard. A longer and more detailed version of this paper is available at: http://cs-cert.unisa . ac.za/internet/research/

\section{References}

[1] A. Cypher. The structure of users' activities. In D. A. Norman and S. W. Draper, editors, [10], chapter 12, pages 243-264. Lawrence Erlbaum Associates, Publishers, Hilldale, New Jersey, 1986.

[2] R. H. Guttman and A. G. M. ans P Maes. Agent-mediated electronic commerce: a survey. Knowledge Engineering Review, 13:147-159, 1998.

[3] M. G. Helander and H. M. Khalid. Modeling the customer in electronic commerce. Applied Ergonomics, 31:609-619, 2000.

[4] C. Lewis and D. A. Norman. Designing for Error. In D. A. Norman and S. W. Draper, editors, User Centred System Design. New Perspectives on Human-Computer Interaction, chapter 20, pages 411-432. Lawrence Erlbaum Associates, Publishers, Hilldale, New Jersey, 1986. 
[5] J. Maree. The internet bookshop business model, with specific reference to amazon.com. Mousaion, XVii(1):76-101, 1999. (Unisa Publication).

[6] J. Nielsen. Usability Engineering. AP Professional, Boston, 1993.

[7] J. Nielsen. "Top Ten Mistakes" Revisited Three Years Later. Web Document. http://www.useit.com/alertbox/990530.html, May 2 1999.

[8] J. Nielsen. The Top Ten New Mistakes of Web Design. Web Document. http://www.useit.com/alertbox/990530.html, May 301999.

[9] J. Nielsen. Success Rate: The Simplest Usability Metric. Web Document. http://www.useit.com/alertbox/20010218.html, February 182001.

[10] D. A. Norman and S. W. Draper, editors. User Centred System Design. New Perspectives on Human-Computer Interaction. Lawrence Erlbaum Associates, Publishers, Hilldale, New Jersey, 1986.

[11] B. O'Conaill and D. Frohlich. Timespace in the workplace: Dealing with interruptions. In Proceedings of ACM CHI'95 Conference on Human Factors in Computing Systems, volume 2 of Short Papers: Workplaces and Classrooms, pages 262-263, 1995.

[12] R. M. O'Keefe and T. McEachern. Web-based customer decision support systems. Communications of the ACM, 41:71-78, 1998.

[13] P. Paper. Making Online Information Usable. http://www.world std.com/ uieweb/online.htm.

[14] R. A. Peterson, editor. Electronic Marketing and the consumer. Sage, London, 1997.

[15] F. Phillips, A. Donoho, W. W. Keep, W. Mayberry, J. M. McCann, K. Shapiro, and D. Smith. Electronically Connecting Retailers and Customers: Interim Summary of an Expert Roundtbale. In /14], chapter 7, pages 101-122. 1997.

[16] S. J. Ravden and G. I. Johnson. Evaluating Usability of Human-Computer Interfaces: A Practical Method. John Wiley and Sons, 1989.

[17] J. Reason. Human Error. Cambridge University Press, 1990.

[18] K. Renaud and R. Cooper. Feedback in Human-Computer Interaction - Characteristics and Recommendations. South African Computing Journal, (26), 2000.

[19] J. W. Senders and N. P. Moray. Human Error. Lawrence Erlbaum, Hillsdale, New Jersey, 1991.

[20] M. Singh, A. K. Jain, and M. P. Singh. E-Commerce over communicators: Challenges and solutions for user interfaces. In Proceedings of the ACM Conference on Electronic Commerce (EC-99), pages 177-186, N.Y., Nov. 3-5 1999. ACM Press.

[21] R. Tilson, J. Dong, S. Martin, and E. Kieke. A Comparison of Two Current E-Commerce Sites. In ACM I6th International Conference on Systems Documentation, Web Navigation, pages 87-92, 1998. 